\title{
O PROCESSO DE ENFERMAGEM DURANTE O PRÉ NATAL COMO INSTRUMENTO NA IDENTIFICAÇÃO DE PROBLEMAS PARA A INTERRUPÇÃO DA AMAMENTAÇÃO
}

Valéria Pereira Vellozo vavellozoenf@gmail.com

INTRODUÇÃO: A partir de 2.001, a Organização Mundial de Saúde, recomenda o aleitamento materno exclusivo até os 6 meses de idade, período este preconizado como ideal para prevenir mortes como diarreia e pneumonia, duas principais causas de morte nessa faixa etária No Brasil, menos de $40 \%$ das crianças são amamentadas até os seis meses de idade. Cabe ao profissional, durante o pré-natal ter a habilidade de escuta e julgamento clínico para identificar diagnósticos para futuros problemas na amamentação. Estes diagnósticos são possíveis através da resolução do Cofen-358/2009 que dispõe sobre a Sistematização de Enfermagem e a Implantação do Processo de Enfermagem. OBJETIVO: Identificar diagnósticos de enfermagem durante 0 pré-natal que possam dificultar ou interromper a amamentação e montar uma estratégia para que este processo seja eficaz. DESCRIÇÃo METODOLÓGICA: Trata-se de uma revisão integrativa referente aos últimos 10 anos realizada através de pesquisa bibliográfica, elaborado através de artigos científicos, periódicos, documentos disponibilizados pela internet, além, de livros e manuais do Ministério da Saúde. RESULTADOS: Dentre os diagnósticos para interrupção da amamentação, pode-se citar: falta de adesão, comportamento de saúde propenso a risco, nutrição desiquilibrada menor do que as necessidades corporais, fadiga, manutenção do lar prejudicada, conhecimento deficiente, controle emocional instável, desesperança, distúrbio na imagem corporal, paternidade ou maternidade prejudicada, processos familiares disfuncionais, risco de vínculo prejudicado, desempenho de papel ineficaz, risco de binômio mãe-feto perturbado, processo de criação de filhos ineficaz, risco de processo de criação de filhos ineficaz, amamentação ineficaz. CONCLUSÃo: Além dos diagnósticos precoces para que o processo de amamentação seja eficaz, muitos outros fatores estão relacionados como entender que o aleitamento materno não é de responsabilidade somente da mãe, e sim da família, comunidade, governo e empregadores. Os benefícios trabalhistas como licença maternidade de 6 
meses, creche no local de trabalho e pausas para amamentar, aumentam os índices de amamentação prolongada e que não seja interrompida antes do prazo mínimo de 6 meses.

Palavras-chave: Amamentação. Processo de enfermagem. Gravidez. 